\title{
Ownership and use of long-lasting insecticidal nets for malaria prevention in Butajira area, south-central Ethiopia: complex samples data analysis
}

Adugna Woyessa ${ }^{1,2^{*}}$, Wakgari Deressa ${ }^{2}$, Ahmed $\mathrm{Ali}^{2}$ and Bernt Lindtjørn ${ }^{3}$

\begin{abstract}
Background: Despite the encroaching of endemic malaria to highland-fringe areas above 2000 meters above sea level in Ethiopia, there is limited information on ownership and use of mosquito nets for malaria prevention. Thus, this study was designed to assess long-lasting insecticidal nets (LLIN) possession and use for malaria prevention in highland-fringe of south-central Ethiopia.

Methods: A multi-stage sampling technique was employed to obtain household data from randomly selected households using household head interview in October and November 2008. Household LLIN possession and use was assessed using adjusted Odds Ratio obtained from complex samples logistic regression analysis.

Results: Only less than a quarter (23.1\%) of 739 households interviewed owned LLINs with more differences between low (54.2\%) high (3.5\%) altitudes $\left(X^{2}=253, P<0.001\right)$. Higher LLIN ownership was observed in illiterate (adj.OR 35.1 [10.6-116.2]), male-headed (adj.OR 1.7 [1.051-2.89]), owning two or more beds (adj.OR 2.7 [1.6-4.6]), not doing draining/refilling of mosquito breeding sites (adj.OR 3.4 [2.1-5.5]) and absence of rivers or streams (adj.OR 6.4 [3.5-11.8]) of household variables. The presence of $\geq 2$ LLINs hanging (adj.OR 21.0 [5.2-85.1]), owning two or more LLINs (adj.OR 4.8 [1.3-17.5]), not doing draining/refilling of mosquito breeding sites (adj.OR 4.2 [1.3-13.6]), low wealth status (adj.OR 3.55 [1.04-12.14]), and $<1$ km distance from absence of rivers or streams (adj.OR 3.9 [1.2-12.1]) of households was associated with more likely use of LLIN. The LLIN ownership was low in the highlands, and most of the highland users bought the bed nets themselves.

Conclusions: This study found a low household LLIN ownership and use in the highland-fringe rural area. Therefore, improving the availability and teaching effective use of LLIN combined with removal of temporary mosquito breeding places should be prioritized in highland-fringe areas.
\end{abstract}

Keywords: Long-lasting insecticidal nets, Ownership, Use, Highland-fringe, Ethiopia

\section{Background}

Current malaria control strategies in Ethiopia include indoor residual spraying (IRS) and long-lasting insecticidal nets (LLINs) to prevent malaria vectors biting humans inside houses. Moreover, other interventions such as effective case management and malaria rapid diagnostic

\footnotetext{
* Correspondence: woyessaa@yahoo.com

${ }^{1}$ Ethiopian Public Health Institute, P.O. Box 1242, Gulelle Sub-City, Addis Ababa, Ethiopia

${ }^{2}$ School of Public Health, College of Health Sciences, Addis Ababa University, P. O. Box 9086, Addis Ababa, Ethiopia

Full list of author information is available at the end of the article
}

tests (RDTs) are parts of the malaria control, prevention and elimination strategies [1]. Adequate evidence has been generated regarding mosquito nets provide a substantial degree of protection against deaths and illnesses from malaria [2-6]. But, community benefits depend also on factors related to net use, house condition, poverty, and behavior of malaria vectors [7-10]. The utilization of ITN has been widely advocated following the launch of the Roll Back Malaria (RBM) in 1998, aimed at halving malaria burden by 2010 through increased LLINs coverage among vulnerable groups $[11,12]$. 
The mosquito net for malaria prevention was first introduced as a piloting scheme in the late 1990s in the northern part of Ethiopia [13]. This countrywide survey showed there was a low coverage of mosquito nets in 1999, but found high willingness of respondents to use nets in the future [13]. In 2000, an estimated $0.2 \%$ of households in areas $<2,000$ meters above sea level (masl) in Ethiopia owned ITN [14]. Aggregated data from the demographic health survey 2005 showed that in areas $<2,000$ masl household ITN coverage risen to $6.4 \%$ in 2005 [14], Thus, in 2004, the Ethiopian Government launched a rapid scaling-up of ITN distribution and coverage that targeted households in areas at risk of malaria, below 2,000 masl [15], and followed by intensive application of other key malaria interventions since 2005 [1]. Subsequently, the LLIN coverage reached $65.6 \%$ coverage in 2007 [16], 95.0\% of nets surveyed in areas < 2,000 m were LLINs. Most nets owned were nets distributed free to beneficiaries by the Federal Ministry of Health since 2005. Thus, the LLINs were primarily blue, family size (i.e. $180 \times 180 \times 150 \mathrm{~cm}$ ), rectangular Perma$\mathrm{Net}^{\ominus} 2.0$ (Vestergaard Frandsen, Copenhagen, Denmark); $94.3 \%$ of ITNs were reportedly $<3$ years old [16].

Various studies showed that malaria even reaches high altitude areas laying between 2,100 and 2,400 masl [17-21]. In fact malaria transmission intensity is low in highlands, and malaria control programme prioritize populations living in malarious areas, most often located below 2,000 masl in Ethiopia [1]. Malaria epidemics at highlands are associated to abnormal weather conditions [18,22].

A recent study in similar study area has shown the importance of malaria in the high altitudes [21], which might be partly related to the warming climate. However, there is limited information regarding LLINs use in the Ethiopian highlands, especially among population living between 2,000 and 2,500 masl. These areas have been susceptible to repeated epidemic phenomenon of different magnitudes [18,22]. Such information can be important to improve planning malaria control program and selection of appropriate interventions in these areas. The objectives of this study were to assess ownership and use of LLINs in rural Butajira area in the southcentral Ethiopian highlands.

\section{Methods}

\section{Study area and population}

This study was conducted in six kebeles (or the smallest administrative units) in the Butajira area, which is located about $130 \mathrm{~km}$ south of Addis Ababa. Those kebeles are parts of Butajira Rural Health Program Demographic Surveillance Site [23]. Administratively, the study was done South Nations Nationalities People Regional State and Meskan and Mareko Districts. The study area is part of an altitudinal transect, which is situated between 1,800 and 2,300 masl. Malaria is endemic with the highest transmission towards the lowlands as described in our previous work [21]. There were 58,335 people living in the Butajira DSS in 2008. Half (50.1\%, $\mathrm{n}=29,243)$ of the population were females. Of the total population, $46 \%(n=26,834)$ of the people lived in our study areas. Malaria is one of the important causes of sicknesses in Butajira area. Above one-thirds (32.3\%, 19,923 of 61,654 ) of malaria suspected people consulted out-patient department of Butajira and Enseno Health Centres, and Butajira Hospital were found microscopically confirmed malaria cases between 2004 September and 2010 August [24].

\section{Sample size calculation}

Household dataset of malaria prevalence study was used for the LLIN ownership and use study. Thus, the sample size determined to estimate malaria prevalence $(n=750)$ in the present study area [21], was believed adequate for this study. Since part of the present study areas was located above 2,000 $\mathrm{m}$ and not covered with LLIN distribution, it was assumed that difference in LLIN ownership differ between the two areas.

\section{Study design and sampling procedure}

A multi-stage sampling technique was employed to obtain data from a cross-sectional household survey. This sampling involved three stages such as kebeles, villages and households. Six kebeles (Hobe, Bati Lejano, Dirama, Shershera Bido, Yeteker and Wurib) were randomly sampled from a total of ten, which are part of demographic surveillance site in Butajira area. Those kebeles were stratified into low, mid-level, and high altitudes. The 750 households were then sampled randomly from the six kebeles and recruited from 16 villages, using probability proportion to size sampling methods (Figure 1).

\section{Household survey data}

This is a cross-sectional survey that we did from 21st October to 6th November 2008. Household heads or their representatives were interviewed on socio-demographic and on household asset. Information on the possession of nets and its condition was collected using interview and observation. Data collectors estimated and recorded the distance of a nearby stream or river from each study household. This study considered a river or stream that is available throughout the year as permanent water body. This study considered LLIN use as reportedly at least a person has slept under a net the night prior to the survey. Handheld Global Positioning System (Garmin eTrex ${ }^{\ominus}$, USA) was used to measure altitudinal location of households. The altitude readings were recorded with a 7-9 m precision. 


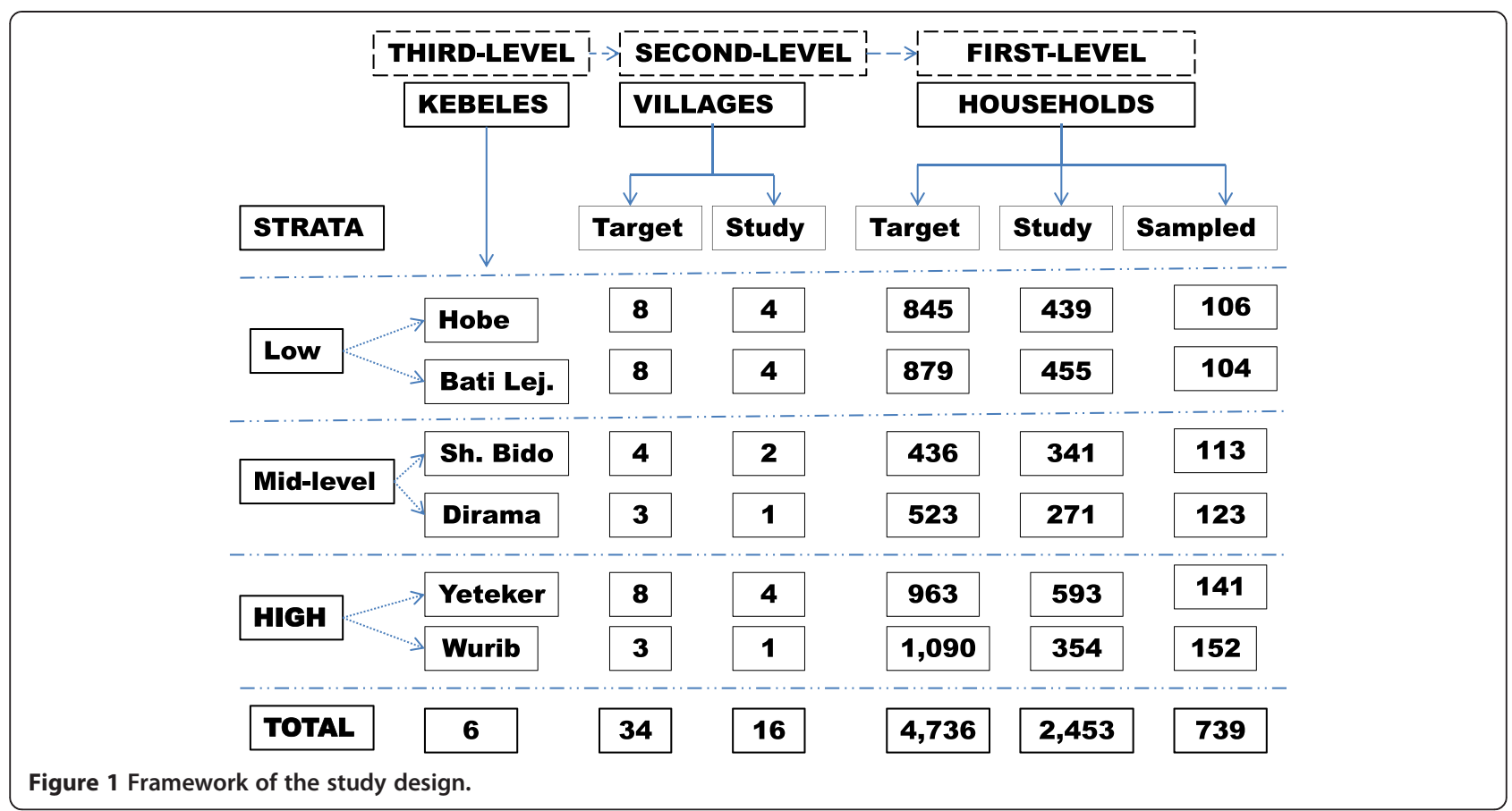

This study is complied with Standards for Reporting of Diagnostic Accuracy guidelines (STARD) to improve the quality of reporting [25].

\section{Data management and statistical analysis}

The principal investigator and an experienced research assistant from the Butajira DSS did the daily field supervision and cross-checking of the completed questionnaire. Data entry and cleaning were conducted using Epi Info version 6 (CDC, Atlanta, USA). The PASW (Predictive Analytics Software) version 20.0 statistical package (IBM Corp, Armonk, NY, USA) was used for data analysis. Descriptive statistics were performed to analyse the characteristics of the sample. Bivariate and multivariate logistic regression analysis were carried out to identify predictors of the ITNs ownership and usage. Only a few households possessed ITN in mid-level stratum, and consequently aggregated with the low altitude stratum (or $<2000 \mathrm{~m}$ ), simply for the convenience of data analysis. Planning of antimalarial interventions has been targeted to geographical areas below 2,000 m, except in epidemic situations. Variables in the bivariate were selected for the multivariate based on a prior knowledge. Then, those with significance value in the bivariate were included in the multivariate. Otherwise household gender was maintained in the final model for ITN ownership. A $P<0.05$ was considered statistically significant.

Household wealth index was computed using Principal Component Analysis (PCA) in SPSS software. Similar studies also used PCA to construct a relative household wealth index $[17,26,27]$. Ownership of household assets, type of usual water sources, type of product, and house construction material were used to build the wealth index as input to PCA. Factorability of the data set was checked using Kaiser-Meyer-Oklin and Bartlett's Test of Sphericity [28]. Eleven variables with greatest weights were loaded on the first principal component and the wealth index varied from -0.256 to 13.27 . Finally, all households were categorized into three categories including "lowest" ranked group $(30.9 \%, \mathrm{n}=228)$, followed by the "middle" ranked group $(35.7 \%, \mathrm{n}=264)$, and finally the top third in the "higher" ranked group (33.4\%, $\mathrm{n}=247)$.

\section{Complex samples data analysis}

This study used data obtained through complex sample. This sampling utilized cluster sampling of kebeles, villages and households. Thus, households within clusters are more similar than households randomly sampled from the population as a whole. This sampling design effectively reduces the information contained in each degree of freedom, which is called design effects [29]. Complex sample violates the assumptions of independence of observations compelling to correct for design effects during data analysis. A study showed that data analysis that do not consider correcting for design effects leads to underestimation of standard errors and resulting to significance tests that are inappropriately sensitive [30].

A common practice to account for appropriate modelling of the complex sample is computing weights for each individual in the data set as described [31]. Briefly, 
weighting is used to correct disproportional sample sizes and adjust the collected data to represent the population from which the sample was drawn. The weight a case has is usually a function of the likelihood of inclusion in the sample. To adjust such distortion within a sample, every case will be assigned a weighting factor, by which the corresponding data is multiplied. This factor is determined by the proportion of the respective group or stratum in the population divided by the proportion of that group or stratum in the sample (the inverse of the sample fraction in each group).

In order to obtain a weighting factor for each case (or household), we used a formula: weighting factor equals $\%$ in population divided by $\%$ in sample. The weighting factor for each sample household was obtained. The calculated values were assigned to each sample and saved as a new variable using SPSS syntax. The other main important step in accounting for design effects is adjusting or normalizing weights. Weights were adjusted by dividing the weight by the mean of weights. Similarly, the adjusted weighting were saved to the dataset for each case and accounted for all statistic operations. Moreover, the association of predictor variables and outcome was estimated using unadjusted and adjusted odds ratio obtained from Complex Samples Logistic Regression Model.

\section{Ethical considerations}

The study obtained ethical clearance from the Institutional Review Board of the College of Health Sciences of the Addis Ababa University, and from the Ministry of Science and Technology of Ethiopia. A written consent is obtained from the South Nations Nationalities People Regional State and Meskan and Mareko Districts. Individual informed consent was obtained from all household heads or their representatives. The necessary health education was given to the households on malaria control and prevention as well as personal protection after interview.

\section{Results}

\section{Characteristics of respondents}

This study used data from interview of 739 households. The response rate was 95\% (739 of 750 households). Above half of the respondents (54.9\%, 406 of 739) were females. The age range of participants was 18-99 years, with a mean $( \pm S D)$ age of $39.2( \pm 14.9)$ years. Most of the households were male-headed $(70.4 \%)$. The average family size per household was 5.14; family members slept in the house prior night to the survey were slightly lower than the actual family size (5.07) (data not shown). Table 1 shows the household and socio-demographic characteristic of study participants.

\section{LLINs possession and use}

Below a quarter $(23.1 \%, \mathrm{n}=171)$ of the 739 households surveyed, owned at least an LLIN, with a mean of 1.54 [95\% CI 1.45-1.63] LLINs per household. Household LLIN ownership was higher in low altitude $(n=155)$ than in high altitude $(n=16)$ (Table 2). Below half (47.4\%) of the households possessing $\geq 2$ LLINs in which all of them were from low altitude.

Among net-owning households, 83.0\% (142 of 171) had a family member who slept under a net the night prior to the survey. Of the households reportedly use their nets $76.1 \%$ (108 of 142) had nets with holes. LLINs with holes showed differences between households located at low $(78.5 \%, \mathrm{n}=106)$ and high $(28.6 \%, \mathrm{n}=2)$ altitudes $\left(X^{2}=9.1, P=0.003\right)$.

\section{Main reasons for non-possession of LLIN}

More than three-fourths $(76.9 \%, \mathrm{n}=568)$ of the households did not have any LLIN during the survey (Table 1). A few of those households $(13.2 \%, \mathrm{n}=75$ ) had net previously. Main reasons respondents cited for non-possession of LLIN during the survey were: do not know sources of LLIN and not available in the area $(61.4 \%, \mathrm{n}=212)$, worn out and discarded $(19.4 \%$, $\mathrm{n}=67)$, believed LLIN do not protect/not important $(14.5 \%, \mathrm{n}=50)$, and shortage of money and narrow sleeping space $(4.6 \%, n=16)$ (data not shown).

For households reportedly using their LLIN $(n=142)$, the main sources of LLIN at low altitude $(n=135)$ were health facilities $(\mathrm{n}=39,28.7 \%)$, District Health Office $(\mathrm{n}=95,70.5 \%)$ and NGO $(\mathrm{n}=1,0.7 \%)$; whereas at high altitude $(n=7)$ health facilities $(n=3,42.3 \%)$, market/ shop $(n=3,43.0 \%)$ and other sources $(n=1,14.8 \%)$ (Data not shown).

\section{Determinants of LLINs possession and use}

This study found household LLIN ownership associated with various household factors such as socio-demographic, status of practising mosquito source reduction, other breeding places instead of permanent water body and number of beds in the house (Table 3). Household heads with no formal education had above 35-fold higher LLIN ownership compared to those with formal education. Household characteristics such as absence of main water body (above 6-fold), not practising mosquito source reduction (more than 3-fold) and presence of two and more beds in the household were significantly associated with increased household LLIN possession than their counterparts. Maleheaded households were also associated to increased LLIN possession than female-headed households. The households with LLIN observed hanging, two and more number of net owned, not practising source reduction and farming occupation showed statistically significant association with highly likely to use LLIN. Of those, the presence of more 


\begin{tabular}{|c|c|c|c|c|}
\hline \multirow[t]{2}{*}{ Household characteristics } & \multicolumn{3}{|c|}{ Altitudinal strata } & \multirow{2}{*}{$\begin{array}{l}\text { Pearson } \\
\text { chi-square; } \\
P \text {-value }\end{array}$} \\
\hline & Low $(n=286)$ & High $(n=453)$ & Total $(\mathrm{N}=739)$ & \\
\hline Respondent gender & & & & $1.4 ; 0.2$ \\
\hline Male & $121(42.3)$ & $212(46.8)$ & $333(45.1)$ & \\
\hline Female & $165(57.7)$ & $241(53.2)$ & $406(54.9)$ & \\
\hline Household-head gender & & & & $0.2 ; 0.6$ \\
\hline Male & $192(67.1)$ & $312(68.9)$ & $504(68.2)$ & \\
\hline Female & $94(32.9)$ & $141(31.1)$ & $235(31.8)$ & \\
\hline Education status & & & & $49.4 ;<0.001$ \\
\hline No schooling at all & $32(11.2)$ & $1(0.2)$ & $33(4.5)$ & \\
\hline Schooling* & $254(88.8)$ & $452(99.8)$ & 706 (95.5) & \\
\hline Wealth status & & & & $17.3 ;<0.001$ \\
\hline Low & $107(37.4)$ & $121(26.7)$ & $228(30.9)$ & \\
\hline Middle & 77 (26.9) & $187(41.3)$ & $264(35.7)$ & \\
\hline Higher & $102(35.7)$ & $145(32.0)$ & $247(33.4)$ & \\
\hline Number of beds & & & & $9.5 ;<0.002$ \\
\hline 1 & $206(72.0)$ & $370(81.7)$ & $576(77.9)$ & \\
\hline $2-5$ & $80(28.0)$ & $83(18.3)$ & $163(22.1)$ & \\
\hline Mosquito source reduction & & & & $78.9 ;<0.001$ \\
\hline No & $207(72.4)$ & $176(38.9)$ & $383(51.8)$ & \\
\hline Yes & 79 (27.6) & $277(61.1)$ & $356(48.2)$ & \\
\hline Permanent water body & & & & $177.6 ;<0.001$ \\
\hline None & $106(37.1)$ & $5(1.1)$ & $111(15.0)$ & \\
\hline$<1 \mathrm{~km}$ & $96(33.6)$ & $236(52.1)$ & $332(44.9)$ & \\
\hline$\geq 1 \mathrm{~km}$ & $84(29.4)$ & $212(46.8)$ & $296(40.1)$ & \\
\hline Occupation farming & & & & $9.2 ; 002$ \\
\hline No & 96 (33.6) & $203(44.8)$ & $299(40.5)$ & \\
\hline Yes & $190(66.4)$ & $250(55.2)$ & $440(59.5)$ & \\
\hline
\end{tabular}

*Read and write to complete grade 12 .

LLIN hanging in a household is a good predictor of net usage (Table 4).

\section{Discussion}

The present study showed that LLIN use was highest for households owning more LLIN in <2, $000 \mathrm{~m}$ areas, where the government had distributed bed nets to all households. LLIN possession was low in the highlands, and most of the highland users bought the bed nets themselves. Interestingly, the poor, families with low education status living in the lowlands and adjacent to potential mosquito breeding sites used bed nets more than others, probably reflecting that perceived risk of malaria is more important than wealth and educational status.

There are some limitations in the present study. This study used data obtained using a cross-sectional household survey of LLIN ownership. Because of the seasonal differences in malaria risk as found in recent study in the same study area [21,32], Consequently, the present finding of LLIN use might be biased and under estimated as malaria risk was low during 2008 compared to 2009. Household LLIN use was obtained by self-report and that may be subject to social-desirability bias. This might be resulting in an overestimation of LLIN usage as a previous study reported [33]. Secondly, this study was a cross-sectional survey done during a peak malaria transmission season, and we might thus have overestimated the real estimate of net usage. A previous study has shown seasonal differences in net utilization in highland areas [34]. The data analysis considered complex samples into account and avoided reporting biased information. Despite these limitations, this study has shown some strengths to draw valuable conclusions that might help in improving designing malaria interventions at 
Table 2 Relationships of household characteristics of and ITN ownership status in Butajira area, Ethiopia, OctoberNovember 2008

\begin{tabular}{|c|c|c|c|c|}
\hline \multirow[t]{2}{*}{ Household characteristics } & \multicolumn{3}{|c|}{ Household own LLINs } & \multirow{2}{*}{$\begin{array}{l}\text { Pearson } \\
\text { chi-square; } \\
P \text {-value }\end{array}$} \\
\hline & No $(n=568)$ & Yes $(n=171)$ & Total $(\mathrm{N}=739)$ & \\
\hline Respondent gender & & & & $0.78 ; 0.4$ \\
\hline Male & $261(46.0)$ & $72(42.1)$ & $333(45.1)$ & \\
\hline Female & $307(54.0)$ & $99(57.9)$ & $406(54.9)$ & \\
\hline Household-head gender & & & & $3.8 ; 0.05$ \\
\hline Male & $377(66.4)$ & $127(74.3)$ & $504(68.2)$ & \\
\hline Female & $191(33.6)$ & $44(25.7)$ & $235(31.8)$ & \\
\hline Education status & & & & $89.2 ;<0.001$ \\
\hline No schooling at all & $3(0.5)$ & $30(17.5)$ & $33(4.5)$ & \\
\hline Schooling & $565(99.5)$ & $141(82.5)$ & $706(95.5)$ & \\
\hline Wealth status & & & & $21.7 ;<0.001$ \\
\hline Low & $153(26.9)$ & $75(43.9)$ & $228(30.9)$ & \\
\hline Middle & $224(39.4)$ & $40(23.4)$ & $264(35.7)$ & \\
\hline Higher & 191 (33.6) & $56(32.7)$ & $247(33.4)$ & \\
\hline Number of beds & & & & $13.2 ;<0.001$ \\
\hline 1 & $460(81.0)$ & $116(67.8)$ & $576(77.9)$ & \\
\hline $2-5$ & $108(19.0)$ & $55(32.2)$ & $163(22.1)$ & \\
\hline Mosquito source reduction* & & & & $60.0 ;<0.001$ \\
\hline No & $250(44.0)$ & $133(77.8)$ & $383(51.8)$ & \\
\hline Yes & $318(56.0)$ & $38(22.2)$ & $356(48.2)$ & \\
\hline Distance of permanent water body & & & & $76.6 ;<0.001$ \\
\hline No permanent water body & $51(9.0)$ & $60(35.1)$ & $111(15.0)$ & \\
\hline$<1 \mathrm{~km}$ & $260(45.8)$ & $72(42.1)$ & $332(44.9)$ & \\
\hline$\geq 1 \mathrm{~km}$ & $257(45.2)$ & $39(22.8)$ & $296(40.1)$ & \\
\hline Occupation farming & & & & $5.5 ; 02$ \\
\hline No & $243(42.8)$ & $56(32.7)$ & $299(40.5)$ & \\
\hline Yes & $325(57.2)$ & $115(67.3)$ & $440(59.5)$ & \\
\hline Altitudinal Strata & & & & $253.0 ;<0.001$ \\
\hline Low & $131(23.1)$ & $155(90.6)$ & $286(38.7)$ & \\
\hline High & $437(76.9)$ & $16(9.4)$ & $453(61.3)$ & \\
\hline
\end{tabular}

*Refilling \& draining of mosquito breeding sites.

highland-fringe areas. This study tried to explicitly examine the use of LLINs by all household members, which makes it is different from previous studies that focused only on the vulnerable groups. The populations at high altitude are presumably at increased risk of epidemics without suitable interventions.

The low LLIN ownership observed is similar to a previous study [35], and also comparable to another study [9]. The LLIN use in this study was the highest compared with the Ethiopian 2007 MIS [16] while similar in a highland area of Kenya [36]. The present finding of LLIN ownership in areas $>2,000$ masl, which is beyond the altitude limit for LLIN distribution and scaled-up interventions, is in agreement with the recent finding of country wide survey in 2011 [37]. It was found that net use is associated with malaria exposure, and low net use in highland areas with low malaria transmission might not be surprising, though the bed net distribution mechanisms differed.

The present finding of increased net possession in illiterate household heads is in contrast with an earlier study in Ethiopia [38]. The finding related to educational status and LLIN ownership can be more explained by a recent study that demonstrated knowledge in malaria prevention and control might not result from formal education only, but also other sources such as non-formal and informal education [39]. The present study showed that households with additional beds had 
Table 3 Predictors of household ITN ownership $(\mathrm{N}=739)$ obtained from complex samples logistic regression model, Butajira area, Ethiopia, October-November 2008

\begin{tabular}{|c|c|c|c|c|}
\hline Household characteristics & Unadj. OR & $95 \% \mathrm{Cl}$ & adj. OR & $95 \% \mathrm{Cl}$ \\
\hline \multicolumn{5}{|l|}{ No schooling at all } \\
\hline Schooling & 31.3 & $9.4-104.4$ & 35.1 & $10.6-116.2$ \\
\hline Educated & 1 & & 1 & \\
\hline \multicolumn{5}{|l|}{ Wealth status } \\
\hline Low & 1.5 & $1.0-2.2$ & 1.3 & $0.7-2.4$ \\
\hline Middle & 0.5 & $0.3-0.9$ & 0.8 & $0.4-1.5$ \\
\hline High & 1 & & & \\
\hline \multicolumn{5}{|l|}{ Head of household gender } \\
\hline Male & 1.3 & $0.9-2.0$ & 1.7 & $1.05-2.89$ \\
\hline Female & 1 & & 1 & \\
\hline \multicolumn{5}{|l|}{ Number of beds } \\
\hline 1 & 1 & & & \\
\hline$\geq 2$ & 2.1 & $1.4-3.1$ & 2.7 & $1.6-4.6$ \\
\hline \multicolumn{5}{|l|}{ Mosquito source reduction } \\
\hline No & 4.7 & $3.1-7.0$ & 3.4 & $2.1-5.5$ \\
\hline Yes & 1 & & 1 & \\
\hline \multicolumn{5}{|l|}{ Permanent water body } \\
\hline None & 6.5 & $3.9-10.8$ & 6.4 & $3.5-11.8$ \\
\hline$<1 \mathrm{~km}$ & 1.9 & $1.2-2.9$ & 1.1 & $0.6-1.9$ \\
\hline$\geq 1 \mathrm{~km}$ & 1 & & 1 & \\
\hline
\end{tabular}

Table 4 Predictors of household LLIN use $(\mathrm{N}=171)$ obtained from complex samples logistic regression model, Butajira area, Ethiopia, October-November 2008

\begin{tabular}{|c|c|c|c|c|}
\hline Household factors & Unadj. OR & $95 \% \mathrm{Cl}$ & adj. OR & $95 \% \mathrm{Cl}$ \\
\hline \multicolumn{5}{|l|}{ Number of LLINs hanging } \\
\hline 0 & 1 & & & \\
\hline $1-2$ & 12.1 & $3.5-42.4$ & 21.0 & $5.2-85.1$ \\
\hline \multicolumn{5}{|l|}{ Number of ITNs owned } \\
\hline 1 & 1 & & & \\
\hline $2-4$ & 4.3 & $1.5-12.1$ & 4.8 & $1.3-17.5$ \\
\hline \multicolumn{5}{|l|}{ Mosquito source reduction } \\
\hline No & 2.8 & $1.2-6.9$ & 4.2 & $1.3-13.6$ \\
\hline Yes & 1 & & 1 & \\
\hline \multicolumn{5}{|l|}{ Wealth status } \\
\hline Low & 3.3 & $1.1-9.9$ & 3.55 & $1.04-12.14$ \\
\hline Middle & 0.7 & $0.3-1.9$ & 0.51 & $0.15-1.69$ \\
\hline High & 1 & & 1 & \\
\hline \multicolumn{5}{|l|}{ Permanent water body } \\
\hline No permanent water body & 1.3 & $0.5-3.3$ & 1.7 & $0.6-5.4$ \\
\hline$<1 \mathrm{~km}$ & 2.1 & $0.7-5.8$ & 3.9 & $1.2-12.1$ \\
\hline$\geq 1 \mathrm{~km}$ & 1 & & 1 & \\
\hline
\end{tabular}


increased net possession. Obviously, more beds are expected in households with a larger family, and allocate additional nets during the distribution as per the national LLIN distribution strategy [15]. A positive association of household family size and LLIN ownership was documented [36]. The negative association between absence of rivers or streams adjacent to households and LLIN ownership found in the present study is in accordance with a previous study [38]. Following the cessation of main rainy season the creation of transient water pools appears common in areas of flat terrain. This ecological setting has been considered as suitable for breeding of Anopheles arabiensis, the main malaria vector in Ethiopia, [17,40]. Similarly, Anopheles arabiensis has been recognized as the predominant species that entails malaria transmission in highlands of Ethiopia [18,22], and in the highlands of Kenya [34]. Moreover, an increased net possession in male-headed households was in agreement with a study in Nigeria [41].

The current finding of households with at least an LLIN seen hanging were more likely to use their net is in harmony with other studies $[9,42,43]$. A few of the households surveyed had hanging nets during the survey. A study from Zambia also demonstrated that the strongest factor influencing net utilization was the presence of an LLIN hanging [43]. They reported of those LLINs hanging; only $10 \%$ were not used the previous night. The present finding of about five-fold highly likely to use net in households owning two or more LLINs is in harmony with studies in Ethiopia [9,44], and various African countries [36,45]. LLIN use increase as more number of nets is available within LLIN-owning households. The present result showing increased LLIN use among households not using removal of mosquito breeding places using refilling and draining is in line with another study [46]. This suggesting other malaria prevention activities/products appeared to substitute for nets rather than complements. The finding of higher net use in households living adjacent to rivers or streams than their counterparts is in agreement with a study [47]. Thus, households with increased risk of getting malaria are more aware of the increased risk and more inclined to use protective measures. Households in the low wealth category had higher LLIN use as documented by other studies $[46,48]$.

Since 2007, the Ethiopian malaria control strategy is targeted to achieve $100 \%$ coverage of all households at risk of malaria, <2000 masl. Instead, we observed that above a quarter of the households geographically located between 1,900 masl and 1,999 masl were not covered by net distribution. But the parasitological survey demonstrated the presence of malaria infection throughout those areas [21]. Households located at high altitude, presumably at low malaria risk, got their nets from different sources than those living at low altitude that were obtained through government channels. More interestingly, the ownership of LLIN by more than a third of the households located in areas above 2,000 $\mathrm{m}$ as demonstrated in the MIS 2011 [37], which might imply the importance of improving LLIN distribution that has been limited to areas $<2,000 \mathrm{~m}$.

Presumably, nets with holes owned by poor families were failed to protect man-vector contact and malaria infection. A current study revealed higher proportion of LLINs in poor condition as also found in the MIS 2011 [37]. Increased malaria infection was found in areas < 2,000 masl [32]. Probably, damaged LLIN and low coverage could partly be a failure in ensuring protection of malaria in the present study area. A study found individuals from the most poor households were more likely to sleep under nets with holes compared to the least poor [49]. In order to obtain full protection from malaria infection using LLIN requires possessing an intact net and persistently sleeping under net every night.

\section{Conclusion}

In conclusion, this study shows there is a deficit between the nationally targeted household LLIN ownership and use in the highland-fringe area of south-central Ethiopia. Therefore, malaria interventions should focus on improving the availability and teaching effective LLIN use combined with removal of temporary mosquito breeding places in the populations at risk of highland-fringe areas. Future LLIN ownership and use studies should emphasise on concurrent investigation of individual parasitological status and LLIN condition.

\section{Competing interests}

The authors declare that they have no competing interests.

\section{Authors' contribution}

AW contributed in conception and design, acquisition of data, analysis and interpretation of data, and drafting the manuscript. WD substantially contributed to conception and design of the study and substantially revisiting the drafted paper. AA substantially contributed to conception and design of the study, reviewing the manuscript and revisiting it critically for important intellectual content. BL substantially contributed to conception and design, analysis and interpretation of data and reviewing the manuscript. BL, AA, WD and AW reviewed the paper and all authors approved the final version.

\section{Acknowledgments}

The authors thank study participants for their willingness, data collectors and malaria microscopists for their hard working during the field activities. This article obtained inputs and comments from examiners my (AW) PhD defence and reviewers. I thank them all for their contribution in improving this article. This study was conducted with the financial support of NUFU and University of Bergen, Norway (Project No: NUFUPRO-2007/10121).

\section{Author details}

${ }^{1}$ Ethiopian Public Health Institute, P.O. Box 1242, Gulelle Sub-City, Addis Ababa, Ethiopia. ${ }^{2}$ School of Public Health, College of Health Sciences, Addis Ababa University, P. O. Box 9086, Addis Ababa, Ethiopia. ${ }^{3}$ Centre for International Health, University of Bergen, Bergen, Norway. 
Received: 28 November 2012 Accepted: 28 January 2014

Published: 31 January 2014

\section{References}

1. MOH: National five year strategic plan for malaria prevention and control in Ethiopia: 2006-2010. Unpublished document of the Federal Ministry of Health of Ethiopia. Addis Ababa, Ethiopia; 2006.

2. D'Alessandro U, Olaleye B, Langerock P, Aikins MK, Thomson MC, Cham MK, Greenwood BM, McGuire W, Bennett S, Cham BA: Mortality and morbidity from malaria in Gambian children after introduction of an impregnated bednet programme. Lancet 1995, 345:479-483.

3. Fegan G, Noor AM, Akhwale WS, Cousens S, Snow RW: Effect of expanded insecticide-treated bednet coverage on child survival in rural Kenya: a longitudinal study. Lancet 2007, 370:1035-1039.

4. Lengeler $\mathrm{C}$ : Insecticide treated bednets and curtains for preventing malaria. Cochrane Data System Rev 2004(2):CD000363.

5. Müller O, Traoré C, Kouyaté B, Yazoume Y, Frey C, Coulibaly B, Becher H: Effects of insecticide-treated bed nets during early infancy in an African area of intense malaria transmission: a randomized controlled trail. Bull World Health Organ 2006, 84:120-126.

6. Schellenberg J, Abdulla S, Nathan R, Mukasa O, Marchant TJ, Kikumbih N, Mushi AK, Mponda H, Minja H, Mshinda H, Marcel T, Lengeler C: Effect of large-scale social marketing of insecticide-treated nets on child survival in rural Tanzania. Lancet 2001, 357:1241-1247.

7. Alaii J, Hawley WA, Kolczak MS, ter Kuile FO, Giming JE, Vulule JM, Odhacha A, Oloo AJ, Nahlen BL, Phillips-Howard PA: Factors affecting use of permethrin-treated bed nets during a ranodomized controlled trial in western kenya. Ame J Trop Med Hyg 2003, 68:137-141.

8. Baume C, Reithinger R, Woldehanna S: Factors associated with use and non-use of mosquito nets owned in Oromia and Amhara Regional States, Ethiopia. Malar J 2009, 8:264.

9. Deressa W, Fentie G, Girma S, Reithinger R: Ownership and use of insecticide-treated nets in Oromia and Amhara Regional States of Ethiopia two years after a nationwide campaign. Trop Med Int Health 2011, 16:1551-1561

10. Wiseman V, Scott A, Mcelroy B, Conteh L, Stevens W: Determinants of bed net use in the Gambia: implications for malaria control. Am J Trop Med Hyg 2007, 76:830-836.

11. RBM: Global Strategic Plan: Roll Back Malaria 2005-2015. Geneva: Roll Back Malaria Partnership, WHO; 2005

12. WHO: Twentieth Report. World Health Organization. Expert Committee on Malaria. (Technical Report Series No. 892). Geneva: WHO; 2000.

13. Jima D, Tesfaye G, Deressa W, Woyessa A, Kebede D, Alamirew D: Baseline survey for the implementation of insecticide treated mosquito nets in malaria control in Ethiopia. Ethiop J Health Dev 2005, 19:16-23.

14. Central Statistics Agency of Ethiopia and ORC Macro: Ethiopia Demographic and Health Survey 2005. Addis Ababa and Calverton, MD: Central Statistics Agency and ORC Macro; 2006.

15. MOH: Insecticide Treated Nets: National Strategic Plan for Going to Scale with Coverage and Utilization in Ethiopia, 2004-2007. Addis Ababa: Federal Ministry of Health of Ethiopia; 2004.

16. Jima D, Getachew A, Bilak H, Steketee RW, Emerson PM, Graves PM, Gebre T, Reithinger R, Hwand J: Malaria indicator survey 2007, Ethiopia: coverage and use of major malaria prevention and control interventions. Malar J 2010, 9:58

17. Graves P, Richards FO, Ngondi J, Emerson PM, Shargie E, Endeshaw T, Mosher AW, Hailemariam A, Zerihun M, Teferi T, Ayele B, Mesele A, Yohannes G, Tilahun A, Gebre T: Individual, household and environmental risk factors for malaria infection in Amhara, Oromia and SNNP regions of Ethiopia. Trans R Soc Trop Med Hyg 2009, 103:1211-1220.

18. Negash K, Kebede A, Medhin A, Argaw D, Babaniyi O, Guintran JO, Delacollette C: Malaria epidemics in the highlands of Ethiopia. East Afr Med J 2005, 82:186-192.

19. Tesfaye S, Belyhun Y, Teklu T, Mengesha T, Petros B: Malaria prevalence pattern observed in the highland fringe of Butajira, Southern Ethiopia: a longitudinal study from parasitological and entomological survey. Malar J 2011, 10:153.

20. Woyessa A, Gebre-Michael T, Ali A: An indigenous malaria transmission in the outskirts of Addis Ababa, Akaki Town and its environs. Ethiop J Health Dev 2004, 18:2-7.
21. Woyessa A, Deressa W, Ali A, Lindtjorn B: Prevalence of malaria infection in Butajira area, south-central Ethiopia. Malar J 2012, 11:84.

22. Abeku T, van Oortmarssen GJ, Borsboom G, de Vlas SJ, Habbema JDF: Spatial and temporal variations of malaria epidemic risk in Ethiopia: factors involved and implications. Acta Trop 2003, 87:331-340.

23. Berhane Y, Wall S, Kebede D, Emmelin A, Enquselassie F, Byass P, Muhe L, Andersson T, Deyessa N, Gossaye Y, Högberg U, Alem A, Dahlblom K: Establishing an epidemiological field laboratory in rural areas: potentials for public health research and interventions. Ethiop J Health Dev 1999, 13:1-47.

24. Gemeda A, Wakgari D, Ahmed A, Lindtjørn B: Shifting to Plasmodium Vivax Dominance at Highlands of Ethiopia Following the Countrywide Intensive use of Artemether-Lumefantrine Throughout Endemic Areas Since 2005: Can we Neglect the Role of Climate and Relapse Cases? Addis Ababa, Ethiopia: 13th World Congress on Public Health; April 23-27; 2012.

25. Bossuyt P, Reitsma JB, Bruns DE, Gatsonis CA, Glasziou PP, Irwig LM, Moher D, Rennie D, de Vet HCW, Lijmer JG: The STARD statement for reporting studies of diagnostic accuracy: explanation and elaboration. Clin Chem 2003, 49:7-18.

26. Deressa W, Ali A, Berhane Y: Household and socioeconomic factors associated with childhood febrile illnesses and treatment seeking behaviour in an area of epidemic malaria in rural Ethiopia. Trans $R$ Soc Trop Med Hyg 2007, 101:939-947.

27. Filmer D, Pritchett LH: Estimating wealth effects without expenditure data-or tears: an application to educational enrollments in states of India. Demography 2001, 38:115-132.

28. Pallant J: SPSS Sunvival Manual: A step by step guide to data Analysis using SPSS for Windows. Thirdth edition. New York, USA: Open University Press; 2007.

29. Kish L: Selection techniques for rare traits. In Genetics and the epidemiology of chronic diseases. Public Health Serv Publ 1965, 1163.

30. Johnson D, Elliott LA: Sampling design effects: do they affect the analyses of data from the national survey of families and households? J Marriage Family 1998, 60:993-1001.

31. Osborne J: Best practices in using large, complex samples: the importance of using appropriate weights and design effect compensation. Pract Assess Res Evaluat 2011, 16:1531-7714.

32. Woyessa A, Deressa W, Ali A, Lindtjorn B: Malaria risk factors in Butajira area, south-central Ethiopia: a multilevel analysis. Malar J 2013, 12:273.

33. Skarbinski J, Winston CA, Massaga JJ, Kachur SP, Rowe AK: Assessing the validity of health facility-based data on insecticide-treated bednet possession and use: comparison of data collected via health facility and household surveys-Lindi region and Rufiji district, Tanzania, 2005. Trop Med Int Health 2008, 13:396-405.

34. Atieli H, Zhou G, Afrane Y, Lee MH, Mwanzo I, Githeko A, Yan G: Insecticide-treated net (ITN) ownership, useage, and malaria transmission in the highlands of western Kenya. Parasit Vectors 2011, 4:113

35. Shargie E, Gebre T, Ngondi J, Graves PM, Mosher AW, Emerson PM, Ejigsemahu Y, Endeshaw T, Olana D, Weldemeskel A, Teferra A, Tadesse Z, Tilahun A, Yohannes G, Richard FO Jr: Malaria prevalence and mosquito net coverage in Oromia and SNNPR regions of Ethiopia. BMC Public Health 2008, 8:321.

36. Eisele T, Keating J, Littrell M, Larsen D, Macintyre K: Assessment of insecticide-treated bednet use among children and pregnant women across 15 countries using standard national surveys. Am J Trop Med Hyg 2009, 80:209-214.

37. Ethiopian Health and Nutrition Research Institute: Ethiopia National Malaria Indicator Survey 2011. Addis Ababa: Ministry of Health of Ethiopia; 2012

38. Legesse $Y$, Tegegn A, Belachew T, Tushune K: Ownership and use of treated bed nets in urban communities of Assosa zone, Western Ethiopia. Ethiop J Health Sc 2008, 17:203-212.

39. Appiah-Darkwah I, Badu-Nyarko SK: Knowledge of malaria prevention and control in a Sub-urban community in Accra, Ghana. International journal of tropical medicine. Int I Tropic Med 2011, 6:61-69.

40. Tulu A: Malaria. In The Ecology of Health and Disease in Ethiopia. Edited by Zein A, Kloos H. Colarado: Westview Press; 1993:341-352.

41. Oresanya O, Hoshen M, Sofola OT: Utilization of insecticide-treated nets by under-five children in Nigeria: assessing progress towards the Abuja targets. Malar I 2008, 7:145.

42. Bennett A, Smith SJ, Jambai A, Alemu W, Kabano A, Eisele T: Household possession and use of insecticide-treated mosquito nets in Sierra Leone 6 months after a national mass-distribution campaign. PLOS ONE 2012, 7(5):e37927. 
43. Macintyre K, Littrell M, Keating J, Hamainza B, Miller J, Eisele T: Determinants of hangining and use of ITNs in the context of near universal coverage in Zambia. Health Policy Plan 2012, 27(4):316-325.

44. Dagne $\mathrm{G}$, Deressa W: Knowledge and utilization of insecticide treated mosquito nets among freely supplied households in Wonago Woreda, Southern Ethiopia. Ethiop J Health Dev 2008, 22:34-41.

45. Khan S, Arnold F, Eckert E: Who Uses Insecticide-Treated Nets? A Comparison of Seven Countries in sub-Saharan Africa. Demographic and Health Research Division, Macro International Inc; 2008:28. www.measuredhs.com/pbs/pdf/ WP58/WP58.pdf.

46. Baume C, Franca-Koh AC: Predictors of mosquito net use in Ghana. Malar J 2011, 10:265.

47. Noor A, Moloney G, Borle M, Fegan GW, Shewchuk T, Snow RW: The use of mosquito nets and the prevalence of Plasmodium falciparum infection in rural Soth Central Somalia. PLOS ONE 2008, 3(5):265.

48. Goesch J, Schwartz NG, Decker ML, Oyakhirome S, Borchert LB, Kombila UD, Poetschke M, Lell B, Issifou S, Kremsner PG, Grobusch MP: Socio-economic status is inversely related to bed net use in Gabon. Malar J 2007, 7:60.

49. Githinji S, Herbst S, Kistemann T, Noor AM: Mosquito nets in a rural area of Western Kenya: ownership, use and quality. Malar J 2010, 9:84.

doi:10.1186/1471-2458-14-99

Cite this article as: Woyessa et al:: Ownership and use of long-lasting insecticidal nets for malaria prevention in Butajira area, south-central Ethiopia: complex samples data analysis. BMC Public Health 2014 14:99.

\section{Submit your next manuscript to BioMed Central and take full advantage of:}

- Convenient online submission

- Thorough peer review

- No space constraints or color figure charges

- Immediate publication on acceptance

- Inclusion in PubMed, CAS, Scopus and Google Scholar

- Research which is freely available for redistribution 